Review

\title{
Wolf in Sheep's Clothing: Primary Lung Cancer Mimicking Benign Entities
}

\author{
Annemie Snoeckx ${ }^{\mathrm{a}, *}$, Amélie Dendooven ${ }^{\mathrm{b}}$, Laurens Carp ${ }^{\mathrm{c}}$, Damien Desbuquoit ${ }^{\mathrm{a}}$, \\ Maarten J. Spinhoven ${ }^{\mathrm{a}}$, Patrick Lauwers ${ }^{\mathrm{d}}$, Paul E. Van Schil ${ }^{\mathrm{d}}$, Jan P. van Meerbeeck ${ }^{\mathrm{e}}$, \\ Paul M. Parizel ${ }^{\mathrm{a}}$ \\ a Department of Radiology, Antwerp University Hospital and University of Antwerp, Wilrijkstraat 10, 2650 Edegem, Belgium \\ b Department of Pathology, Antwerp University Hospital and University of Antwerp, Wilrijkstraat 10, 2650 Edegem, Belgium \\ c Department of Nuclear Medicine, Antwerp University Hospital and University of Antwerp, Wilrijkstraat 10, 2650 Edegem, Belgium \\ d Department of Thoracic and Vascular Surgery, Antwerp University Hospital and University of Antwerp, Wilrijkstraat 10, 2650 Edegem, Belgium \\ e Department of Thoracic Oncology, Antwerp University Hospital and University of Antwerp, Wilrijkstraat 10, 2650 Edegem, Belgium
}

\section{A R T I C L E I N F O}

\section{Keywords:}

lung cancer

pulmonary nodule

computed tomography

18F-fluorodeoxyglucose positron emission

tomography

\begin{abstract}
A B S T R A C T
Lung cancer is the most common cancer worldwide. On imaging, it typically presents as mass or nodule. Recognition of these typical cases is often straightforward, whereas diagnosis of uncommon manifestations of primary lung cancer is far more challenging. Lung cancer can mimic a variety of benign entities, including pneumonia, lung abscess, postinfectious scarring, atelectasis, a mediastinal mass, emphysema and granulomatous diseases. Correlation with previous history, clinical and biochemical parameters is necessary in the assessment of these cases, but often aspecific and inconclusive. Whereas ${ }^{18} \mathrm{~F}$-fluorodeoxyglucose $\left({ }^{18} \mathrm{~F}\right.$-FDG) Positron Emission Tomography is the cornerstone in staging of lung cancer, its role in diagnosis of these uncommon manifestations is less straightforward since benign entities can present with increased ${ }^{18}$ F-FDG-uptake and, on the other hand, a number of these uncommon lung cancer manifestations do not exhibit increased uptake. Chest Computed Tomography (CT) is the imaging modality of choice for both lesion detection and characterization. In this pictorial review we present the wide imaging spectrum of CT-findings as well as radiologic-pathologic correlation of these uncommon lung cancer manifestations. Knowledge of the many faces of lung cancer is crucial for early diagnosis and subsequent treatment. A multidisciplinary approach in these cases is mandatory.
\end{abstract}

\section{Introduction}

With more than 1.8 million new annual cases and a case fatality rate of $>90 \%$, lung cancer is the deadliest cancer in men and women worldwide. The disease burden of lung cancer remains still high and is moreover likely to increase in the future [1]. Lung cancer imaging is part of daily routine work in most radiology practices and this certainly will be the case in the future. In symptomatic patients, lung cancer typically presents as a pulmonary mass. Since the majority of patients is diagnosed with clinical stage III or IV, metastatic disease (lymph nodes, adrenal glands, liver, ...) can often be diagnosed at the time of diagnosis on chest CT [2]. With the widespread use of Computed Tomography (CT) detection and recognition of the imaging features of early lung cancers such as pulmonary nodules, nodule with 'cystic airspace' or scar-like lesion, is gaining more attention [3]. Lung cancer can present with a wide spectrum of CT-imaging findings and can mimic pneumonia, abscess, scarring, atelectasis, a mediastinal mass, emphysematous changes and granulomatous diseases. Recognition of the typical lung cancer cases of nodules and masses is often straightforward, whereas diagnosis of these uncommon manifestations is far more challenging. It is evident that correlation with previous history, clinical and biochemical parameters is necessary. Unfortunately, these parameters are often aspecific and inconclusive. Whereas ${ }^{18} \mathrm{~F}$-fluorodeoxyglucose $\left({ }^{18} \mathrm{~F}\right.$-FDG) Positron Emission Tomography (PET) is the cornerstone in staging of lung cancer, its role in diagnosis of these uncommon manifestations is less straightforward since benign entities can present with increased ${ }^{18}$ F-FDG-uptake and on the other hand, a number of these uncommon lung cancer manifestations do not exhibit increased uptake. Numerous techniques for tissue sampling are available, including bronchoalveolar lavage, bronchial brushing, bronchial

\footnotetext{
* Corresponding author.

E-mail addresses: Annemie.snoeckx@uza.be, annemiek.snoeckx@gmail.com (A. Snoeckx), Amelie.dendooven@uza.be (A. Dendooven), Laurens.carp@uza.be (L. Carp), Damien.desbuquoit@gmail.com (D. Desbuquoit), Maarten.spinhoven@uza.be (M.J. Spinhoven), Patrick.lauwers@uza.be (P. Lauwers), Paul.vanschil@uza.be (P.E. Van Schil), Jan.vanmeerbeeck@uza.be (J.P. van Meerbeeck), Paul.parizel@uantwerpen.be (P.M. Parizel).
} 

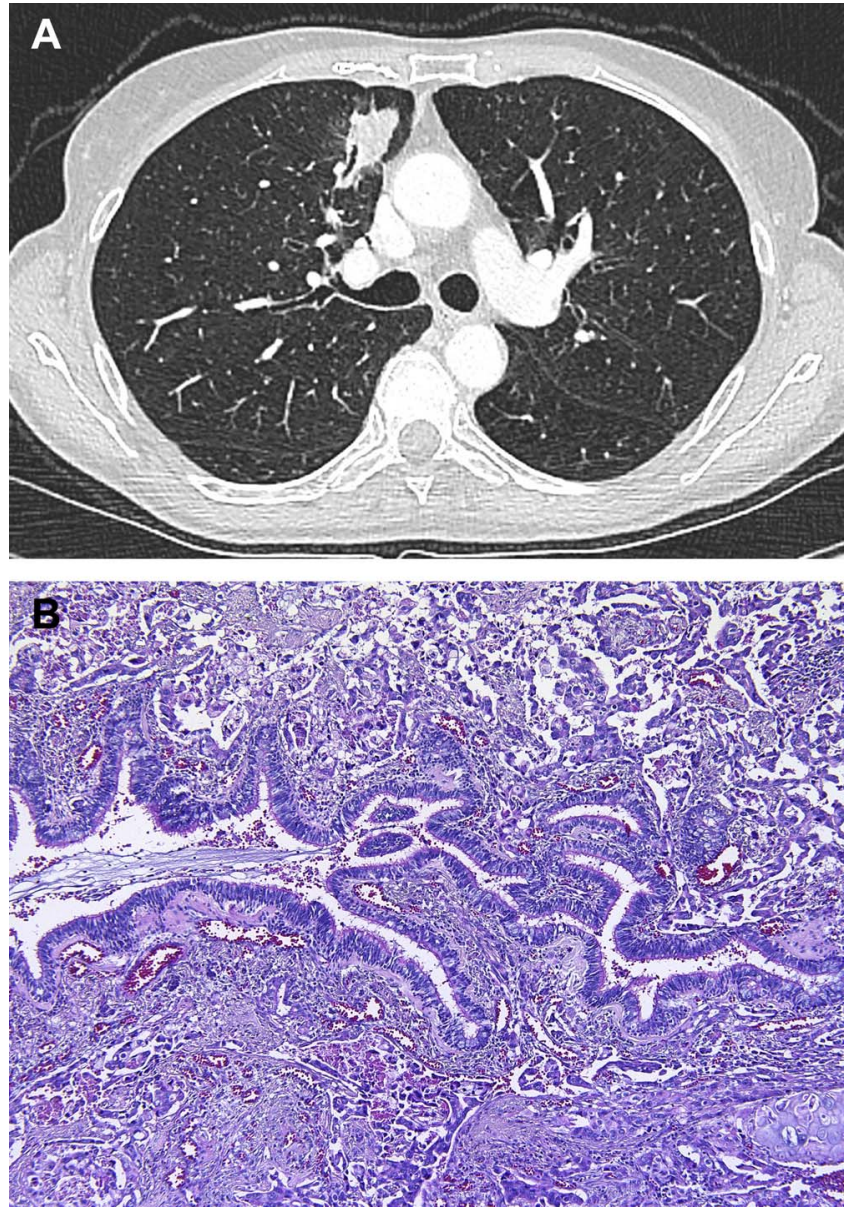

Fig. 1. Axial CT-image in lung window setting (a) in a 55-year-old woman who presented with cough and fever shows an area of consolidation in the right upper lobe. Note the irregular air-filled bronchogram running through the consolidation. This finding is highly suggestive of a tumour (rather than infectious consolidation), in particular adenocarcinoma. Photomicrograph (b) shows an invasive adenocarcinoma with predominant acinar growth in a desmoplastic stroma. Note the tumour surrounding the bronchus with tumour ingrowth in the bronchial wall without mucosal extension (Hematoxylin Eosin (H-E) stain; original magnification, x 100).

and transbronchial biopsy (including endobronchial ultrasound-guided transbronchial needle aspiration) and transthoracic needle biopsy. Obtaining histopathologic proof in these uncommon manifestations is far more challenging due to the unusual morphology (such as cavitation, cystic airspace, miliary pattern, ...), stressing the importance of imaging.

The goal of this pictorial review is to present the wide spectrum of CT-imaging findings as well as radiologic-pathologic correlation of these uncommon lung cancer manifestations.

\subsection{Looks like pneumonia}

Lung cancer can present as a spiculated area of consolidation with air bronchogram, mimicking pneumonia [4]. Findings of a consolidation in a patient clinically presenting with fever should not mislead the radiologist from the possible diagnosis of a tumour. Adenocarcinomas can present with air bronchogram (Fig. 1) and internal bronchial abnormalities such as bubble like lucencies. Bronchial abnormalities that are strongly associated with malignancy in nodules or small masses include a bronchus obstructed abruptly by the tumour, a bronchus penetrating into the tumour with tapered narrowing and interruption and a bronchus that runs around the periphery of the tumour with intact lumen [5]. Bronchial wall thickening proximal to the area of consolidation and associated pleural thickening can point to the

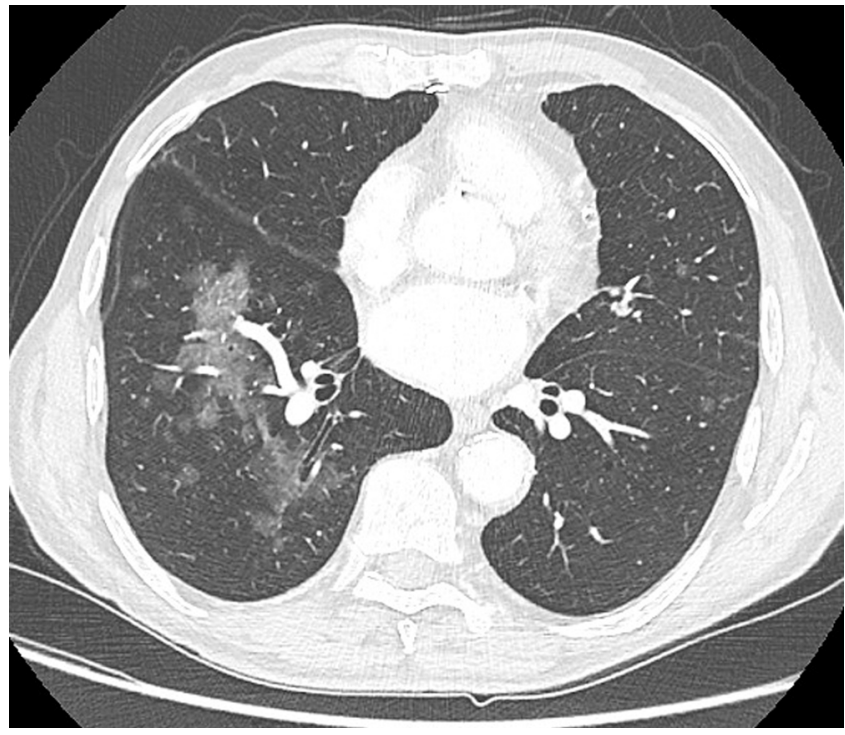

Fig. 2. 78-year-old man who presented with persistent cough. Axial CT-image in lung window setting shows numerous ground glass nodules in the right lower lobe. Note the preservation of normal lung architecture and pulmonary vessels running through the lesions. Follow-up after 3 months showed persistence of the abnormalities. Diagnosis of adenocarcinoma with lepidic growth was confirmed after transthoracic biopsy.

diagnosis of infection rather than tumour [6]. A peripheral distribution of the consolidation and presence of surrounding nodules is also more indicative of tumour [7]. Molecular profiling in this type of lesions is recommended since presence of an air bronchogram is associated with activated Epidermal Growth Factor Receptor (EGFR) mutation [8]. Since pulmonary infections can show increased ${ }^{18} \mathrm{~F}$-FDG-uptake and adenocarcinoma can show low ${ }^{18}$ F-FDG-uptake, the role of ${ }^{18}$ F-FDGPET in these cases is limited $[9,10]$.

Adenocarcinoma with predominant lepidic growth can present on CT as persistent multiple confluent ground glass nodules (Fig. 2). Ground glass is defined as increased attenuation of the lung parenchyma without obscuration of the pulmonary vascular markings on CT [11]. Ground glass abnormalities can be the result of a wide variety of interstitial and alveolar diseases, including opportunistic infections (pneumocystis pneumonia, cytomegalovirus, herpes simplex virus,...), chronic interstitial diseases (hypersensitivity pneumonitis, nonspecific interstitial pneumonia,...), acute alveolar diseases (pulmonary edema, adult respiratory distress syndrome, diffuse alveolar haemorrhage,...), drug toxicity and adenocarcinoma with lepidic growth (formerly called 'bronchioloalveolar cell carcinoma or BAC') [12]. The latter should be on the differential diagnosis list when findings persist after 3 months, the ground glass abnormalities have a more nodular well-defined morphology and/or more solid dense areas ('part-solid' aspect) are associated. Adenocarcinomas with predominant lepidic growth exhibit little or even no uptake on FDG-PET in contrast to infectious causes presenting as ground glass, who paradoxically have a higher glucose uptake $[9,13]$. When diagnosis on initial imaging studies is doubtful, short-term follow-up (one to three months) can give additional information and narrow down the differential diagnosis. Recently, pneumonic type adenocarcinoma was integrated in the 8th edition of the Tumour, Node and Metastasis (TNM) lung cancer classification. The location of the areas of involvement defines the T or M category: T3 if confined to one lobe, T4 if involving different lobes in one lung, and M1a if involving both lungs [14].

\subsection{Looks like an abscess}

Lung cancer presenting as a relatively well-defined mass with internal hypodense aspect due to necrosis or fluid, can mimic a 

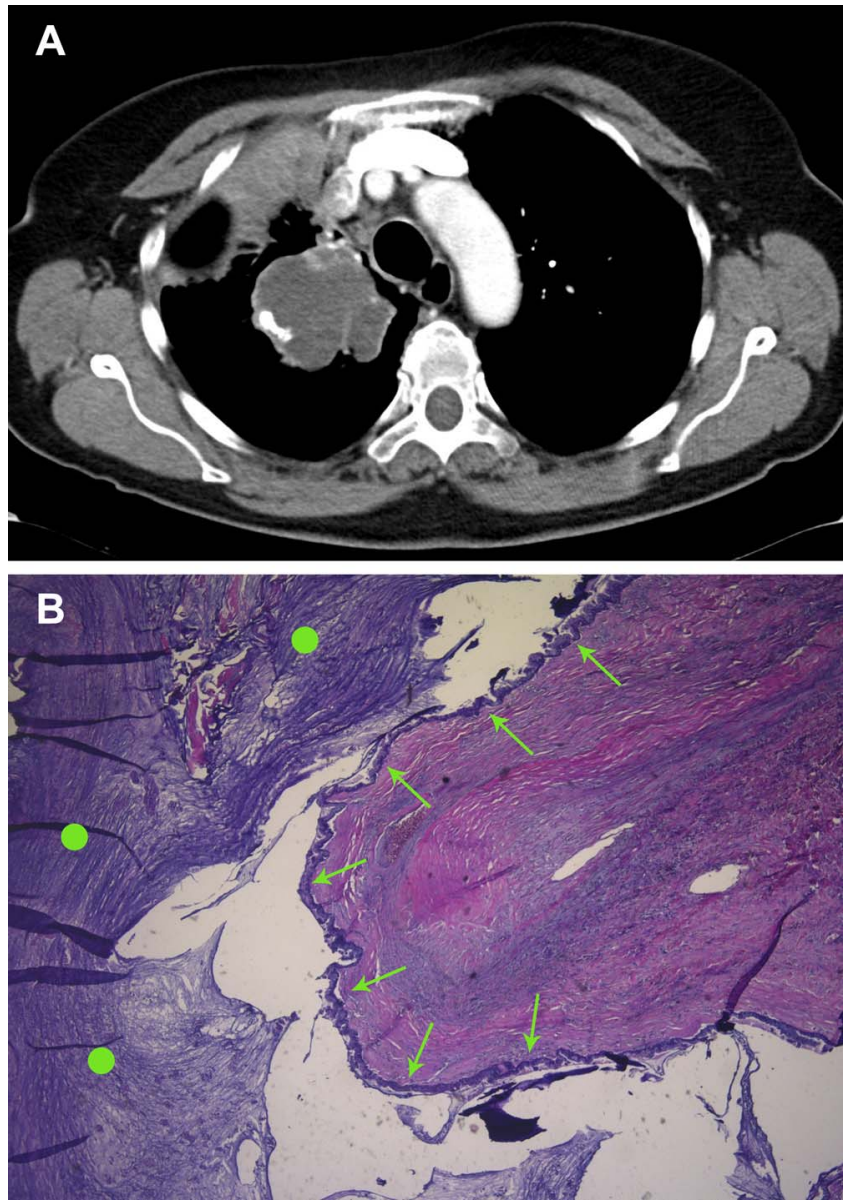

Fig. 3. Axial contrast-enhanced CT-image (a) in a 72-year-old woman who presented with a large lobulated hypodense lesion with only minor peripheral enhancement and no clear soft tissue component. Also note the coarse peripheral calcifications. A lobectomy was performed. Photomicrograph (b) shows abundant areas of mucus (green dots) and a single cell layer of malignant mucinous epithelium lining these tumoral cavities (green arrows) (H-E stain; original magnification, x 40).

pulmonary abscess. In particular this is the case for mucinous tumours and cavitary lung lesions. Mucinous adenocarcinoma is a heterogeneous group of tumours that have the ability to produce mucinous substances. The most common manifestation of a mucinous adenocarcinoma on imaging is that of consolidation, focal or diffuse [15]. Presentation of this tumour as a nodule or cystic mass with peripheral enhancement and intralesional mucus is rare (Fig. 3). Due to the high water content, mucus has a CT-attenuation and signal intensity on Magnetic Resonance Imaging (MRI) similar to that of water. Moreover, it does not enhance after intravenous contrast injection. Transformation can occur in a chronic entrapped mucus collection: water is gradually being reabsorbed and protein concentration increased. The density of mucus will increase on CT, making differentiation with a solid mass more difficult [16]. Mucinous tumours show no or only mild ${ }^{18}$ F-FDGuptake due to an abundant mucin component of the tumour [17]. When patients present with a fluid-filled masslike lesion and clinical signs of infection are absent, a mucinous tumour should be included in the list of differential diagnoses.

Numerous lesions can present on imaging as a solitary cavitary lung mass with air-fluid levels, including lung abscess, lung cancer, fungal infections or haemorraghe into a cavity [4]. A cavity is an area within a mass or nodule that is filled with gas and seen on radiographs or CT as a lucency or low-attenuation area. Differentiation between a benign and malignant solitary cavitary lung mass is challenging since both entities can present with cavitation [18]. In the early phase, abscesses can present as a cavitary mass with internal air-fluid levels caused by
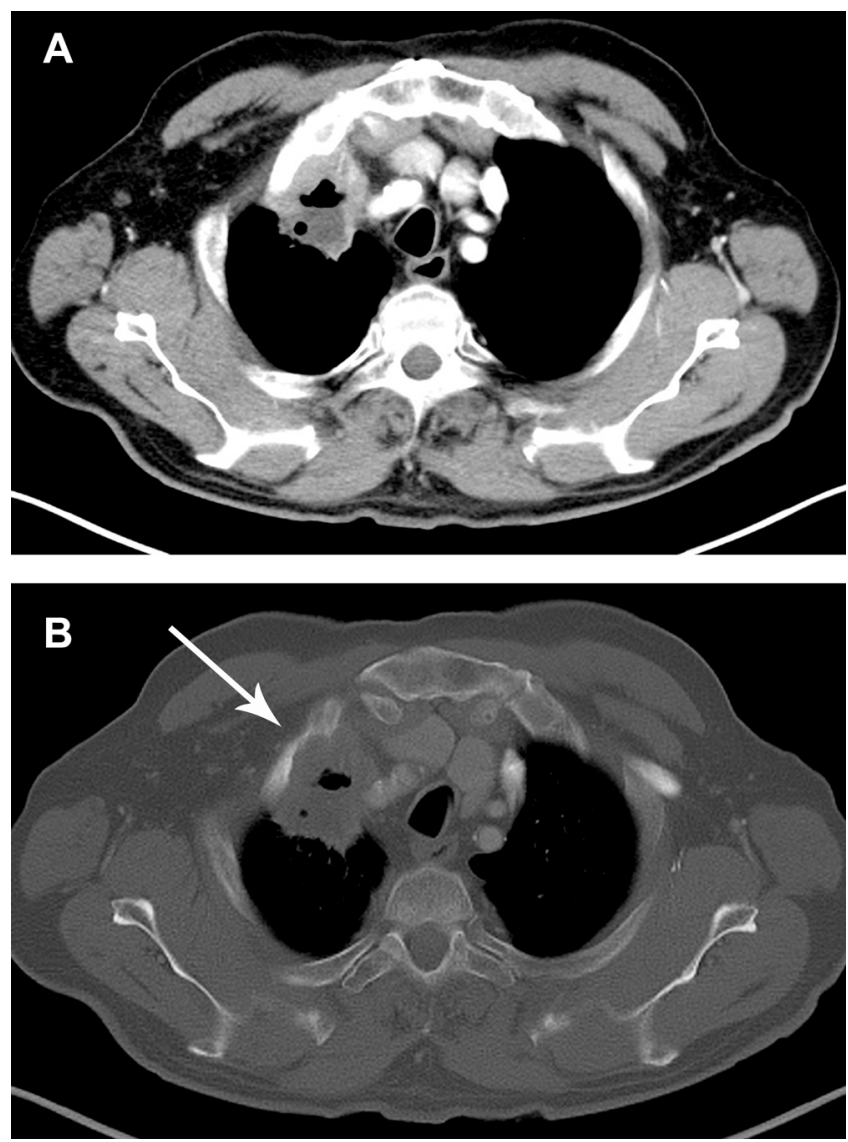

Fig. 4. Axial CT-images in mediastinal window setting (a) in a 68 -year-old man show a heterogeneous thick walled cavitary lesion in the right lung apex with central necrosis and air-fluid level. Images in bone window setting (b) clearly depict the cortical rib erosion adjacent to the lesion (white arrow). This finding is highly suspicious for a tumour. Histopathologic examination after transthoracic biopsy showed squamous cell carcinoma.

necrotic lung tissue. Commonly encountered anaerobic organisms in pulmonary abscesses include Klebsiella pneumoniae, Pseudomonas aeruginosa, Staphylococcus aureus, Nocardia and Actinomyces species. When chronic, lesions can have a more solid aspect. Cavitation in lung cancer (Fig. 4) is relatively common and has been reported in $2-16 \%$ of cases. It is more frequently found in squamous cell carcinomas (80\%) compared to other histologic subtypes $[19,20]$. Cavitary lung lesions are being frequently described as "thick walled" or "thin walled", without specific definitions. The limited number of studies on wall thickness date from the 80's where measurements and evaluation of wall thickness were performed on radiographs [21]. Upon today, wall thickness is an imperfect tool to differentiate benignity from malignancy [20]. Local (bone) destruction and infiltration, presence of enlarged lymph nodes and continuous growth of a cavitary mass or consolidation should strongly suggest the diagnosis of a tumour rather than infection $[19,22]$. Both entities show increased uptake on ${ }^{18}$ F-FDG-PET, making PET less helpful for differentiating benign from malignant aetiology $[10,23]$. In patients with a cavitary mass or consolidation with internal air-fluid levels, correlation with clinical and biochemical parameters is essential. When these do not suggest a possible infectious cause, a more aggressive approach to obtain histopathologic proof may be justified.

\subsection{Looks like scarring}

Lung scars may occur secondary to a number of causes including tuberculosis, which is the commonest cause, as well as bronchiectasis, 


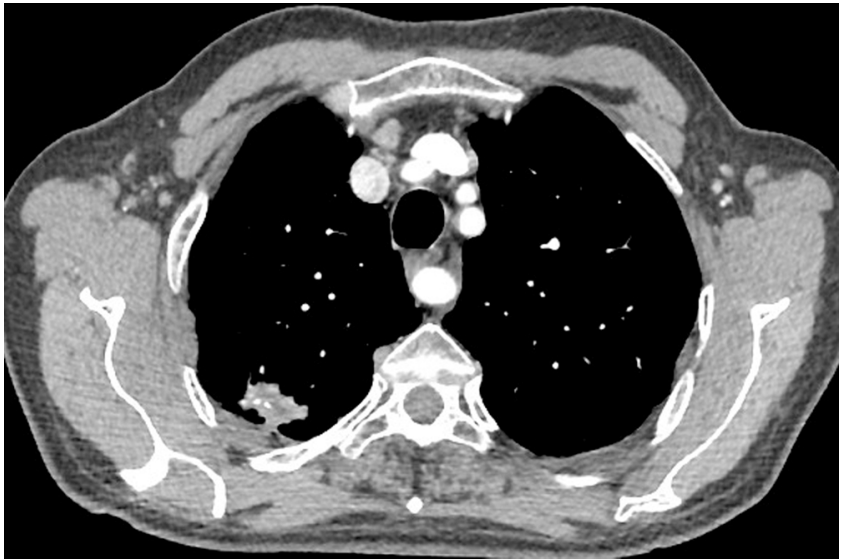

Fig. 5. A 58-year old man with a recent history of tuberculous meningitis presented with persistent cough. A CT-examination was ordered to rule out pulmonary tuberculosis. Axial CT image in mediastinal window setting shows a $2 \mathrm{~cm}$ spiculated nodule posteriorly in the right upper lobe. The nodule contains some hypodense areas and small coarse calcifications that made the lesion more suspicious for lung cancer than for tuberculosis. Histopathology confirmed the diagnosis of primary lung cancer (adenocarcinoma) and tuberculosis was further ruled out.

pulmonary infections, organizing pneumonia, trauma or infarction. The pathogenesis of lung scar carcinoma is still unclear. Lung scar carcinomas (Fig. 5) preferably occur at the predilection sites of lung tuberculosis, in the periphery of the lung, close to the pleura [24]. Lesions tend to be large with diameters more than $5.3 \mathrm{~cm}$ [25]. Diagnosis on imaging of a lung cancer superimposed on pulmonary tuberculosis is challenging and cannot be made on a single examination. Follow-up and correlation with clinical aspects are essential. Enlargement of scar tissue, large lobulated masses with spiculation, pleural retraction, vessel convergence, surrounding ground-glass opacities and mediastinal adenopathies could point out to a lung scar carcinoma [24]. Calcifications are common in scars and have no value in differentiating a scar from a lung scar carcinoma. The presence of calcifications in a nodule or mass does not ensure that the lesion is benign [26]. In addition to the presence of a previous calcified scar (such as in tuberculosis), calcifications in lung cancer can be dystrophic in areas of tumour necrosis or can be caused by calcium deposition within the tumour. The latter is associated with the secretory function of the tumour as seen in mucinous adenocarcinoma [27]. Calcifications in a malignant tumour is uncommon with prevalences reported around 6-7\% [27]. Malignant calcifications (Fig. 6) are more amorphous or punctate whereas benign calcifications are more central, diffuse solid, laminated or popcorn-like. Spiculated nodules with dystrophic calcifications in the lung apex should not be mistaken for an apical scarring. Apical scarring has a typical triangular wedge-shaped morphology with a predominant subpleural localization. Calcified foci may occur and findings are often bilateral. Asymmetric findings in the lung apices and a more nodular aspect should raise concern and close monitoring in these cases is mandatory [28]. Comparing follow-up examinations with the oldest examination available will increase sensitivity to detect subtle changes, indicating a possible malignant nature.

\subsection{Looks like atelectasis}

Atelectasis refers to collapse or incomplete expansion of lung parenchyma and is frequently encountered in radiology practice. Causes are numerous and imaging findings depend on the underlying mechanism. Obstructive atelectasis has a particular imaging appearance, referred to as "drowned lung sign" (Fig. 7). Airways in the obstructed lung parenchyma fill with fluid and become densely consolidated. The volume and imaging aspect of the collapsed segment can be variable: volume loss and increased density can occur, but in some cases the
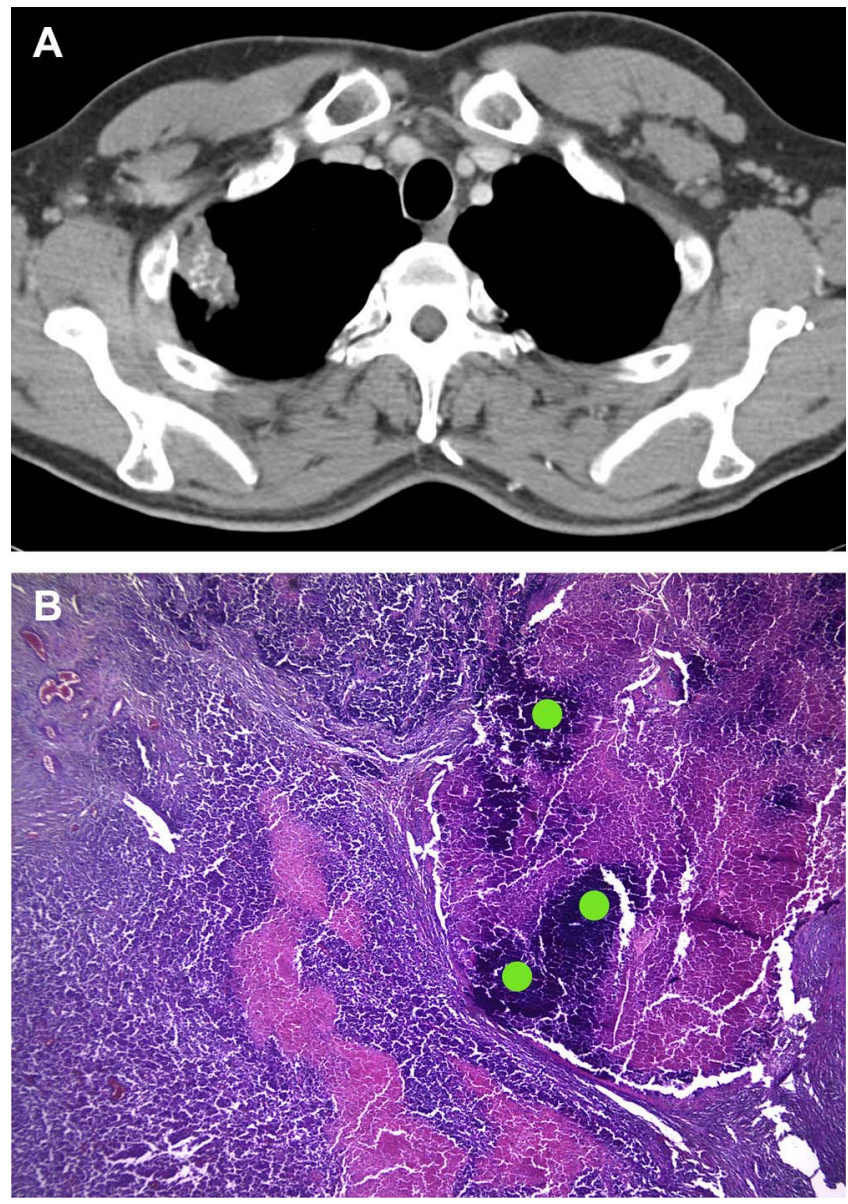

Fig. 6. Incidental finding of a right upper lobe lesion in a 36-year old man who presented with posttraumatic chest wall pain. Axial contrast-enhanced CT in mediastinal window setting (a) shows a $4 \mathrm{~cm}$ spiculated subpleural lesion in the right apex. Findings are asymmetrical with the left apex, where no abnormalities are present. Note the small areas of calcification, which are punctate and amorphous. Photomicrograph (b) shows a poorly differentiated invasive adenocarcinoma with foci of calcifications (green dots) (H-E stain; original magnification, x 40).

segment can even appear more expanded. Findings are related to the severity and duration of the obstruction and on the presence or absence of collateral air drift. When volume loss is present, secondary findings can be seen on imaging, including elevation of the hemidiaphragm and mediastinal shifting [29]. The presence of an air bronchogram does not however exclude an obstructive cause since air drift can be present $[30,31]$. When the obstructing tumour (carcinoma, adenoma, bronchial metastasis, lymphoma, ....) is small, the lesion can be difficult to differentiate from the collapsed lung. A "drowned lung sign" can be the only abnormality seen on CT (Fig. 8) and should alert the radiologist to an obstructive cause and further bronchoscopic evaluation. Compared to $\mathrm{CT},{ }^{18} \mathrm{~F}$-FDG-PET and diffusion weighted MRI can better differentiate obstructing tumour from adjacent obstructive atelectasis [32].

\subsection{Looks like a mediastinal mass}

In aggressive tumour types such as small cell lung cancer (SCLC) and large cell neuroendocrine tumours (LCNEC), the dominant finding can be a mediastinal mass related to lymphadenopathy without clear depiction of the primary lung tumour [33,34]. Diagnosis of lung cancer is straightforward when lymphadenopathies are numerous and confluent with encasement of mediastinal structures. When a solitary mediastinal lymphadenopathy is the only finding, distinction with a primary mediastinal mass can be more challenging (Fig. 9). Adenopathies encountered in aggressive types of lung cancer may typically 

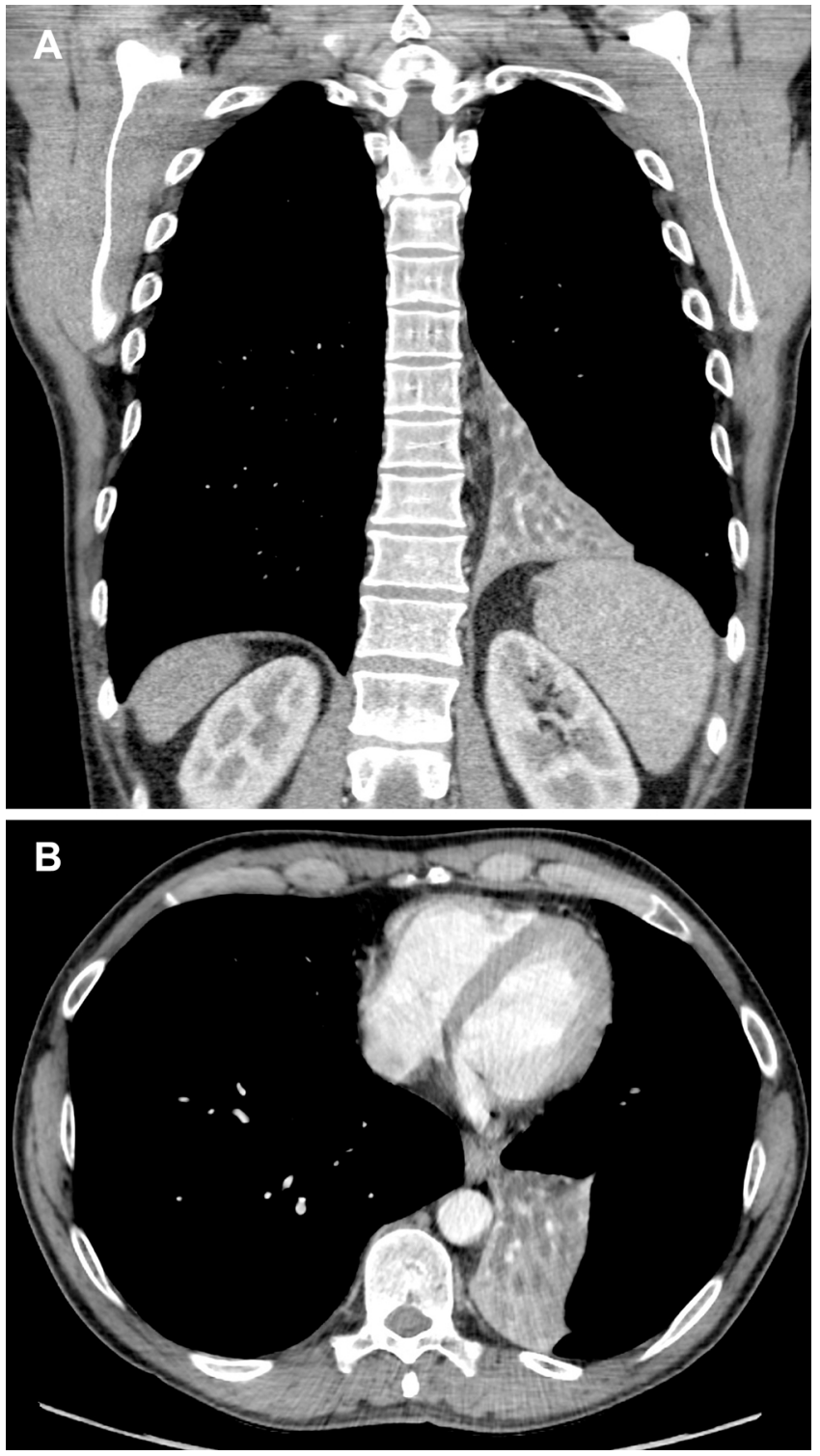

Fig. 7. Coronal (a) and axial (b) contrast-enhanced CT-images in mediastinal window setting show an elevation of the left diaphragm and large consolidation consistent with atelectasis of the left lower lobe. Note the branching tubular low density structures within the consolidated or collapsed lung. Histopathologic examination of the central obstructing mass (which could only be poorly delineated on CT) revealed a squamous cell carcinoma.

exhibit a relatively low attenuation due to necrosis (Fig. 10). CT-images should be scrutinized for other possible signs of malignancy, including small pulmonary nodules (which can harbor the primary tumour), pleural effusion and pleural thickening, pericardial involvement, metastatic disease in bones and upper abdomen. Due to the high metabolic activity of small cell lung cancer and other aggressive tumours, lesions show a high FDG-uptake and PET can aid in detection of the (probable) primary lung tumour [35].

\subsection{Looks like emphysema}

"Lung cancer associated with cystic airspaces" was originally described in 1941 [36]. Although it is rare, it is more frequently encountered and recognized through the widespread use of CT. The pathogenesis is not yet understood. Numerous mechanisms have been proposed. It is unclear if the cystic airspace precedes the development of lung cancer or that tumour growth leads to the formation of a cyst.
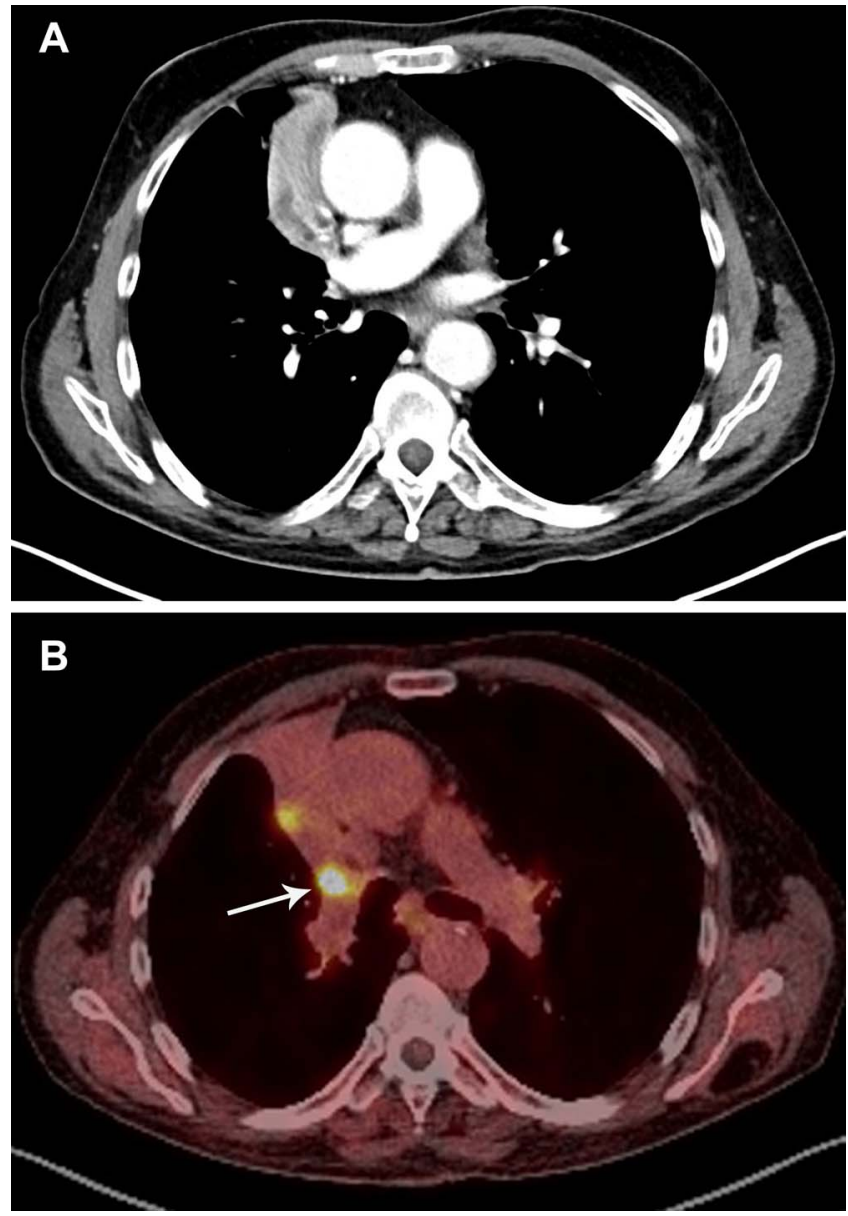

Fig. 8. Axial contrast-enhanced CT (a) shows a paramediastinal area of consolidation with hypodense - mucus filled- bronchogram. The endobronchial obstructive tumor cannot be delineated on CT, but is easily appreciated on FDG-PET (b). Bronchoscopy showed an obstructing, endobronchial lesion which turned out to be a leiomyosarcoma on histopathologic examination.

The latter may be explained by a possible check-valve obstruction at the terminal bronchiolar level by the neoplastic process, leading to formation of the cystic airspace $[37,38]$. Adenocarcinoma is the commonest associated cancer, nevertheless squamous and small cell carcinoma can also be found. A strong association between this disease entity and smoking is noted [39]. Four different morphologic types have been described on imaging: Type I is a nodule or mass extruding from the wall. Type II is a nodule or mass confined to the cystic airspace. Type III is a soft tissue density extending along the wall and Type IV is a soft tissue density intermixed with clusters of cystic airspaces (Fig. 11). Associated emphysema is often but not always present and the association with emphysema remains unclear $[40,41]$. The associated "cystic airspace" on imaging can be misinterpreted as emphysematous changes and the surrounding consolidation or ground glass as superimposed infection. Careful attention should be paid to this lesion when the associated tumour is an adenocarcinoma with lepidic growth, on imaging manifesting as ground glass surrounding the cystic airspaces (Fig. 12). In general lung cancers associated with cystic airspaces exhibit intense uptake on ${ }^{18}$ F-FDG-PET [42]. This is not the case in adenocarcinomas with lepidic growth, where uptake on PET can be minimal or even absent $[43,44]$. Knowledge of this entity, which is gaining more attention lately, is crucial for recognition and early diagnosis. 

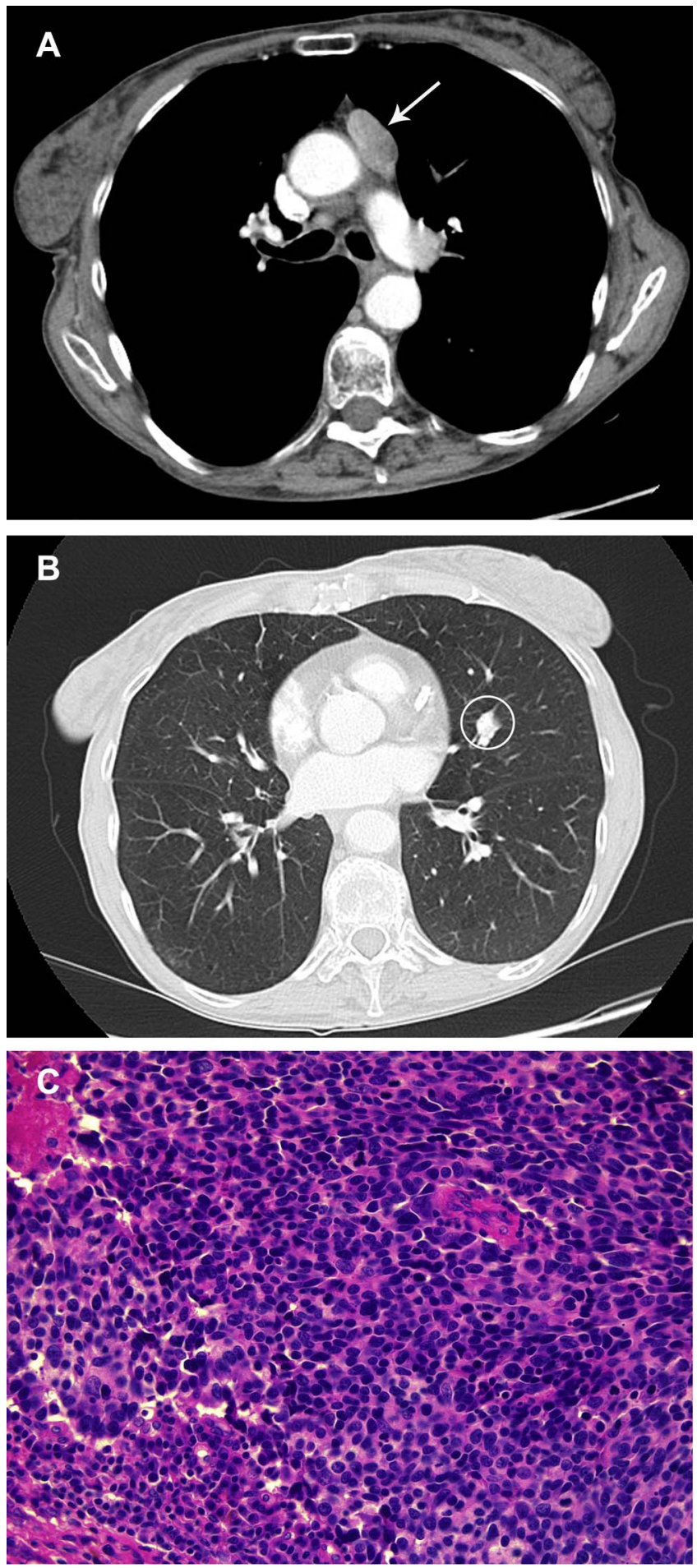

Fig. 9. Axial contrast-enhanced CT-image in mediastinal window setting (a) shows a lobulated well-defined slightly heterogeneous mediastinal mass (white arrow) in a 64year-old woman without any other enlarged mediastinal or hilar lymph nodes. Images in lung window setting (b) show a small pulmonary nodule (white circle). Since this lesion was highly avid on ${ }^{18} \mathrm{~F}$-FDG-PET, this small nodule probably was the primary lung cancer. Photomicrograph (c) of the mediastinal mass (which was resected) demonstrates lymph node invasion by a large cell neuro-endocrine carcinoma (H-E stain; original magnification, $\mathrm{x} 400$ ).

\subsection{Looks like granulomatous disease}

Lung cancer can mimic the wide variety of granulomatous diseases, in particular tuberculosis. A miliary pattern is described as multiple small $(<3 \mathrm{~mm})$ pulmonary nodules of similar size, randomly
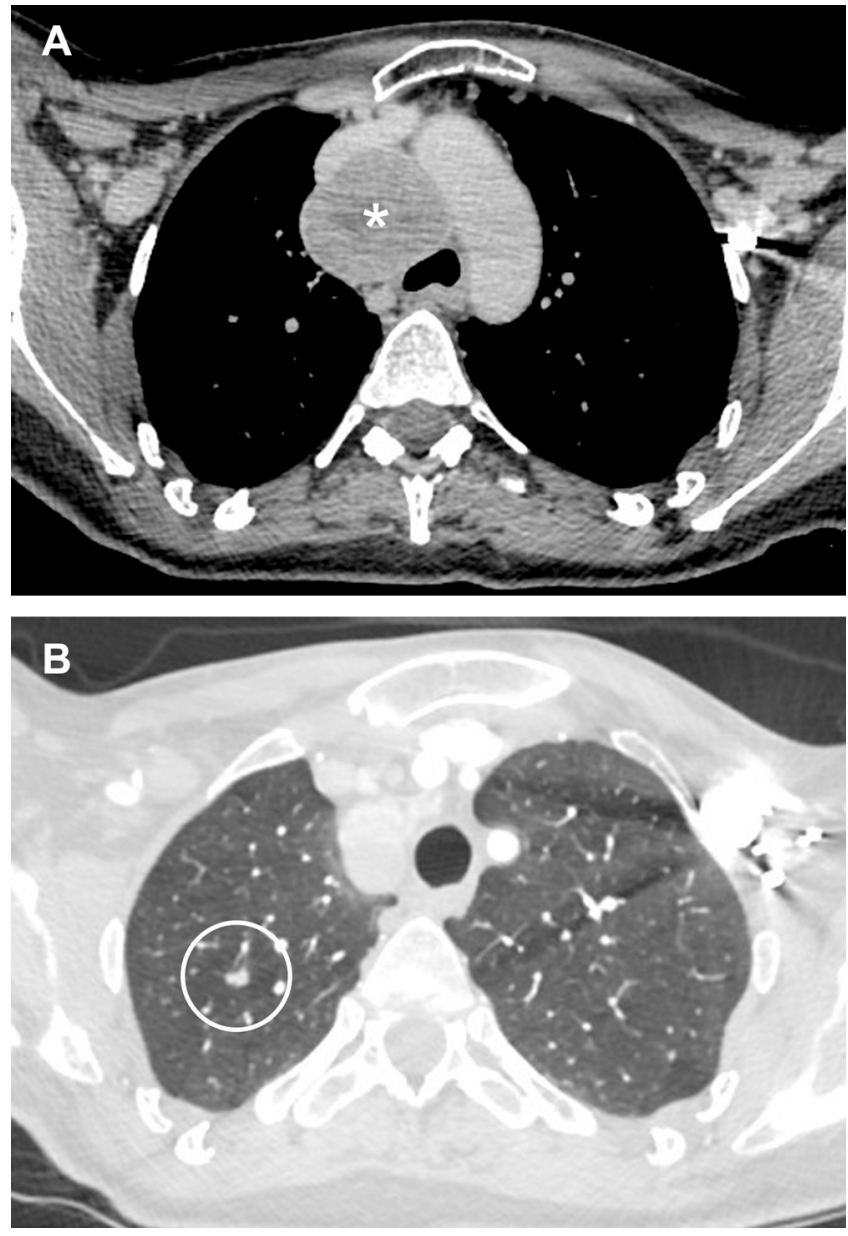

Fig. 10. A 43-year-old woman with a previous history of Marfan syndrome presented with neck pain. As incidental finding on CT angiography (a) of the carotid arteries (to rule out dissection) a well delineated, slightly heterogeneous mediastinal mass was noted (asterisk). Images in lung window setting (b) showed an aspecific micronodule in the right upper lobe (white circle). ${ }^{18}$ F-FDG-PET showed intense uptake in the mediastinal mass and moderate uptake in the small nodule which probably was the primary tumor. Diagnosis of small cell lung carcinoma was made after endobronchial ultrasound-guided biopsy of the mediastinal mass.

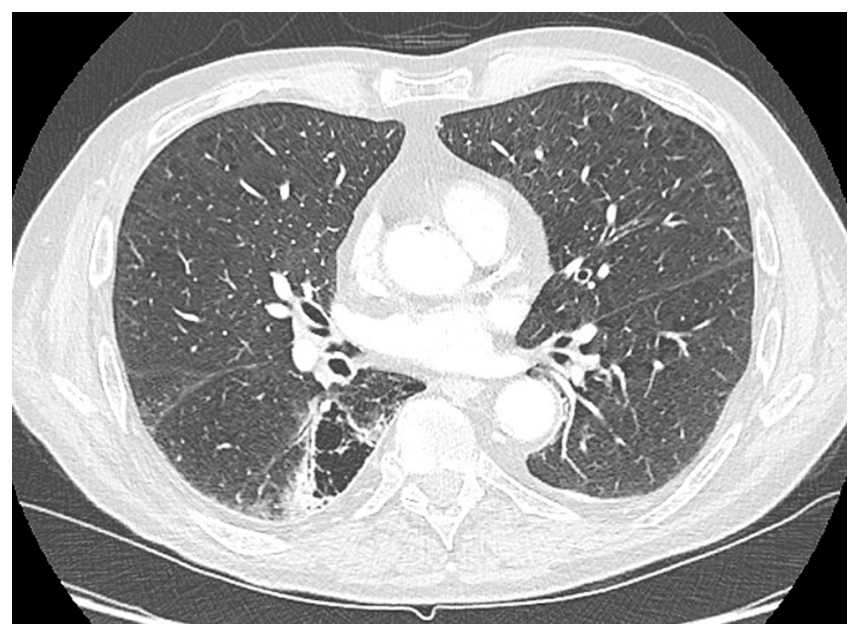

Fig. 11. Axial CT-images in lung window setting in a 78-year-old man show a triangular area of "cystlike" abnormalities in the right lower lobe, surrounded with an area of consolidation. Findings mimic emphysematous changes with superimposed infectious consolidation. Persistence of the lesion after 3 month follow-up made it suspicious for 'lung cancer associated with cystic airspaces', which was confirmed on histopathology (invasive adenocarcinoma). 

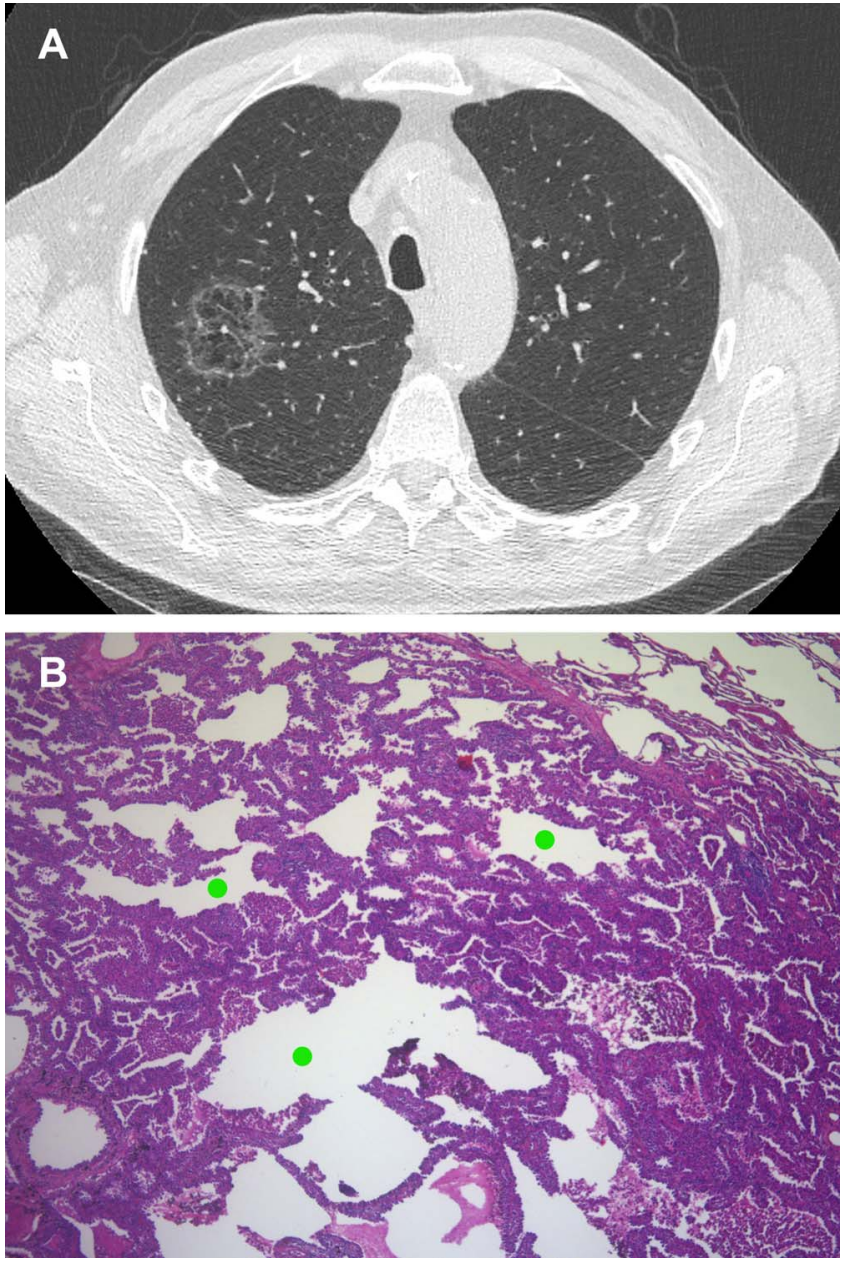

Fig. 12. Axial CT-images in lung window setting (a) in a 74-year-old man with complaints of persistent cough show a $4.8 \mathrm{~cm}$ area of 'cystic airspaces' surrounded by and partially interspersed with ground glass component. Findings were suspicious on imaging for Type IV 'lung cancer associated with cystic airspaces'. A lobectomy was performed. Photomicrograph (b) shows an adenocarcinoma composed of an outer layer with lepidic growth pattern and inner layer with papillary architecture, creating cyst-like spaces (green dots). (H-E stain; original magnification, x 40).

distributed throughout both lungs (Fig. 13). The random aspect of the nodules should be differentiated from those with a centrilobular or perilymphatic distribution as seen in granulomatous disease [11]. Miliary tuberculosis, as result of haematogenous disseminations, should certainly be included in patients presenting with miliary opacities [45]. Other benign entities presenting with a miliary pattern include some forms of sarcoidosis (atypical form where the miliary pattern is less frequent than the classic pattern with perilymphatic spread), fungal diseases (histoplasmosis, coccidioidomycosis, blastomycosis, cryptococcosis), acute extrinsic allergic alveolitis [46-48]. Clinical findings such as fever and severe illness may be indicative of an infectious cause, but can also be absent or more indolent. Miliary lung metastases are usually seen in highly vascular primary malignancies such as renal cell carcinoma, thyroid cancer, bone sarcoma, choriocarcinoma, melanoma, ... It is an uncommon phenomenon in lung cancer indicating a highly aggressive tumour. Most lung cancer patients with miliary lung metastases present with widespread metastatic disease to liver, bone and brain at the time of diagnosis. Small studies may indicate that there is a high rate of EGFR mutations in patients presenting with adenocarcinoma with miliary spread, indicating that this small group of patients may benefit from early treatment with EGFR tyrosine kinase inhibitors $[49,50]$. The broad differential diagnosis of miliary opacities makes correlation with clinical findings essential.
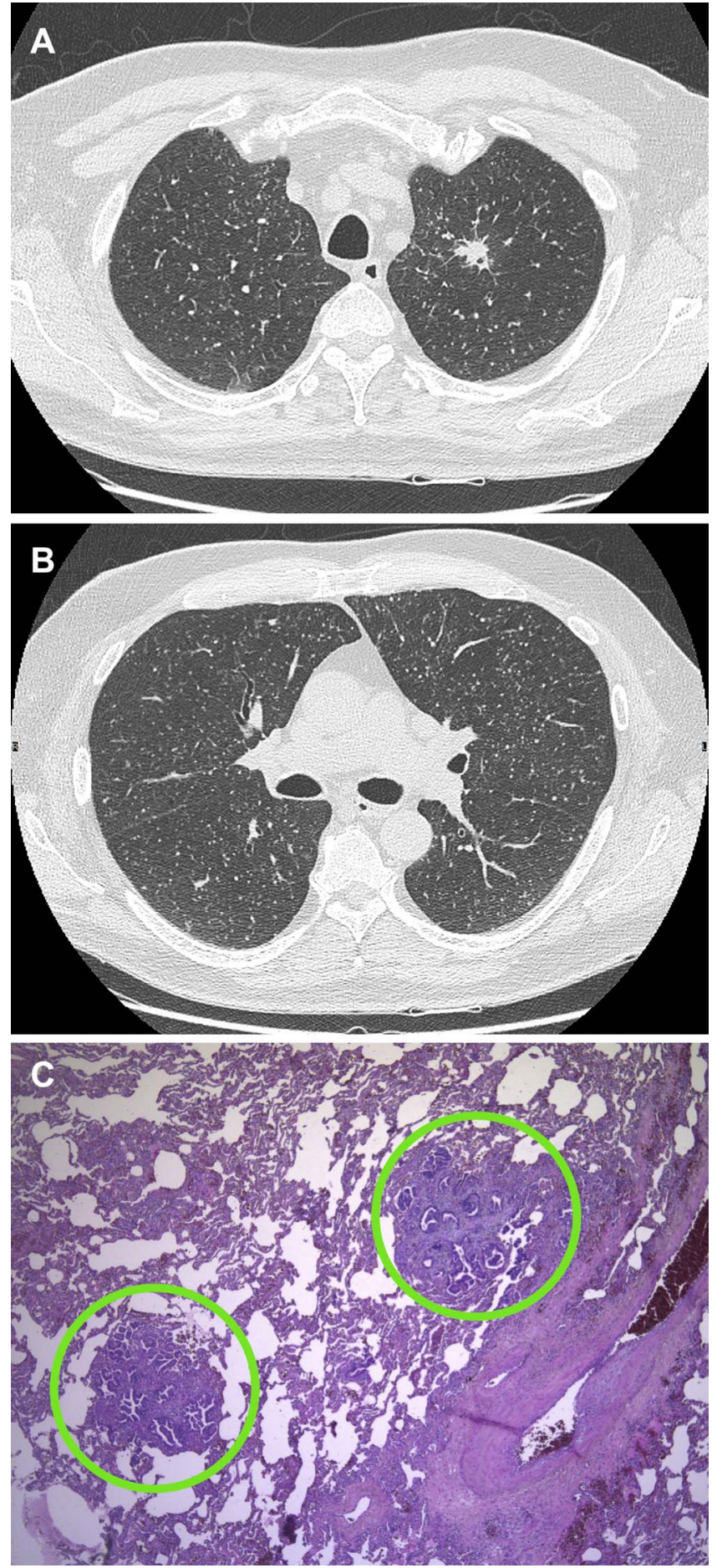

Fig. 13. A 61-year-old man presented with weight loss and cough. Chest radiograph clearly showed a miliary pattern. Axial CT in lung window setting (a,b) confirmed the miliary pattern showing numerous micronodules scattered throughout both lungs and a larger spiculated nodule in the left upper lobe. Since efforts to prove diagnosis of tuberculosis were unsuccessful, patient was referred to our hospital for second opinion and further workup. Surgery with wedge excision was performed. Photomicrograph (c) shows multiple small nodular areas of adenocarcinoma (green circles) (H-E stain; original magnification, $\mathrm{x} 40$ ).

Regarding primary lung cancer presenting as cavitary nodule, it is impossible to differentiate between a malignant and benign etiology based on differences in wall thickness (Fig. 14). Some features may be indicative of a malignant or benign etiology of a cavitary pulmonary nodule, but great overlap exists. A more irregular inner contour and 

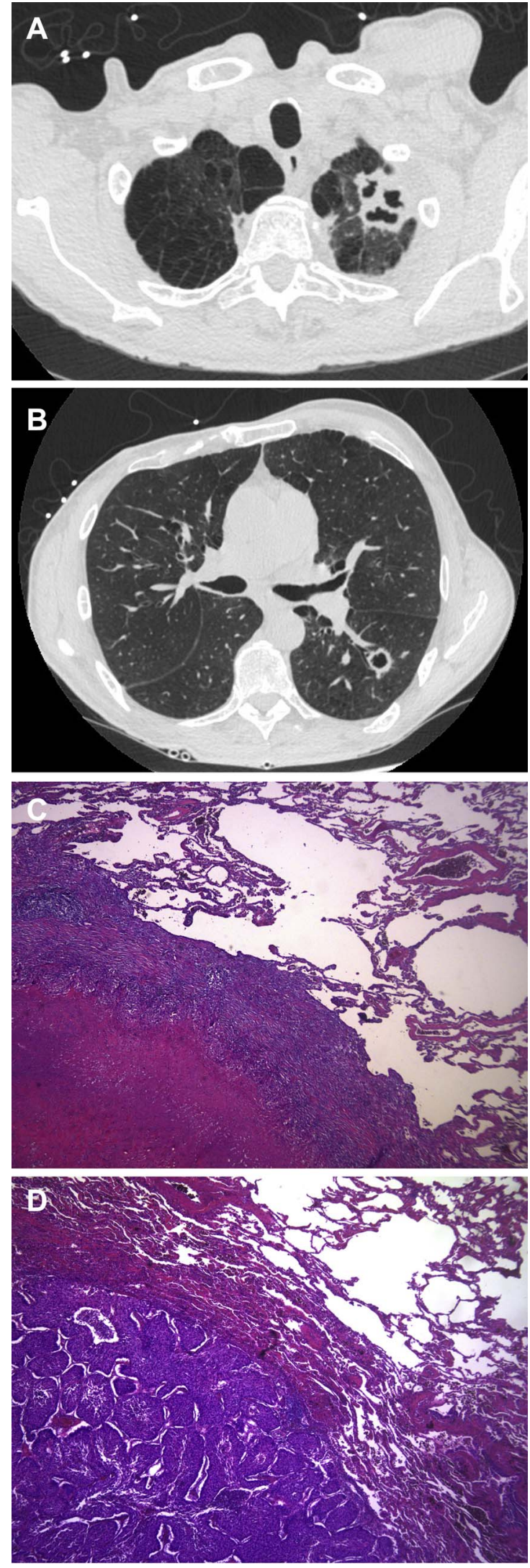

spiculated or lobulated morphology of the nodule might indicate a neoplastic nodule rather than a benign entity. A linear margin, satelite nodules surrounding a cavitary nodule and bronchial wall thickening
Fig. 14. A 59-year-old man presented on axial CT-images with two cavitated lung lesions, one lesion in the apex of the left upper lobe (a) and one in the apex of the left lower lobe (b). The left upper lobe lesion shows a thicker and more irregular wall than the lesion in the left lower lobe which showed a thinner wall with more uniform aspect. Wedge excision of both nodules was performed. Photomicrograph (c) of the cavitary nodule in the left upper lobe shows a necrotizing granuloma, consisting of necrosis and a border of histiocytes. Findings are consistent with tuberculosis (H-E stain; original magnification, $x$ 40). Some acid fast organisms were seen on Ziehl Neelsen stain. Photomicrograph (d) of the nodule in the left lower lobe shows a squamous cell carcinoma consisting of sheets of large tumour cells with some squamous differentiation (H-E stain; original magnification, $\mathrm{x} 40$ ).

are more frequent in benign nodules, including pulmonary tuberculosis, histoplasmosis, aspergilloma and other fungal infections, Wegener granulomatosis, Churg-Strauss syndrome, rheumatoid lung nodule, lymphomatoid granulomatosis, ... [20,22,48]. Correlation with clinical information is essential in these cases. When there are no findings indicating a benign diagnosis, a more aggressive (surgical) approach is warranted.

\section{Conclusion}

Primary lung cancer can have many faces and may mimic numerous benign entities. Early recognition of these uncommon manifestations is key to early diagnosis and subsequent treatment. Dedicated morphological assessment on imaging studies is crucial in order to define a potential malignant nature of the observed findings and is vital for selection of the most beneficial and oncologically valid surgical procedure. A multidisciplinary approach is mandatory in these cases.

\section{Statement of Authorship}

This manuscript represents original work. Neither this manuscript nor one with substantially similar content has been published or is being considered for publication elsewhere. All authors contributed to this manuscript, to the conception and design of this review or acquisition of data. All authors revised the manuscript critically for important intellectual content and approved the final version of the submitted manuscript.

\section{References}

[1] T.-Y.D. Cheng, S.M. Cramb, P.D. Baade, D.R. Youlden, C. Nwogu, M.E. Reid, The International Epidemiology of Lung Cancer: Latest Trends, Disparities, and Tumor Characteristics, J Thorac Oncol. 11 (2016) 1653-1671, http://dx.doi.org/10.1016/ j.jtho. 2016.05.021.

[2] S. Rossi, P. Baili, R. Capocaccia, M. Caldora, E. Carrani, P. Minicozzi, et al., The EUROCARE-5 study on cancer survival in Europe 1999-2007: Database, quality checks and statistical analysis methods, European Journal of Cancer 51 (2015) 2104-2119, http://dx.doi.org/10.1016/j.ejca.2015.08.001.

[3] C. Rampinelli, S.F. Calloni, M. Minotti, M. Bellomi, Spectrum of early lung cancer presentation in low-dose screening CT: a pictorial review, Insights Into Imaging (2016) 1-11, http://dx.doi.org/10.1007/s13244-016-0487-4.

[4] C.M. Walker, G.F. Abbott, R.E. Greene, J.-A.O. Shepard, D. Vummidi, S.R. Digumarthy, Imaging Pulmonary Infection: Classic Signs and Patterns, American Journal of Roentgenology 202 (2014) 479-492, http://dx.doi.org/10. 2214/AJR.13.11463.

[5] J.W. Qiang, K.R. Zhou, G. Lu, Q. Wang, X.G. Ye, S.T. Xu, et al., The relationship between solitary pulmonary nodules and bronchi: multi-slice CT-pathological correlation, Clin Radiol 59 (2004) 1121-1127, http://dx.doi.org/10.1016/j.crad.2004. 02.018 .

[6] T.H. Kim, S.J. Kim, Y.H. Ryu, S.Y. Chung, J.S. Seo, Y.J. Kim, et al., Differential CT features of infectious pneumonia versus bronchioloalveolar carcinoma (BAC) $\mathrm{mi}$ micking pneumonia, Eur Radiol 16 (2006) 1763-1768, http://dx.doi.org/10.1007/ s00330-005-0101-5.

[7] S.L. Aquino, C. Chiles, P. Halford, Distinction of consolidative bronchioloalveolar carcinoma from pneumonia: do CT criteria work? American Journal of Roentgenology 171 (1998) 359-363, http://dx.doi.org/10.2214/ajr.171.2. 9694451.

[8] J. Dai, J. Shi, A.K. Soodeen-Lalloo, P. Zhang, Y. Yang, C. Wu, et al., Air bronchogram: A potential indicator of epidermal growth factor receptor mutation in pulmonary subsolid nodules, Lung Cancer 98 (2016) 22-28, http://dx.doi.org/10. 1016/j.lungcan.2016.05.009.

[9] H.-B. Wu, L. Wang, Q.-S. Wang, Y.-J. Han, H.-S. Li, W.-L. Zhou, et al., 
Adenocarcinoma with BAC features presented as the nonsolid nodule is prone to be false-negative on 18F-FDG PET/CT, Biomed Res Int 2015 (2015) 243681, http://dx. doi.org/10.1155/2015/243681.

[10] Y. Tsushima, U. Tateishi, H. Uno, M. Takeuchi, T. Terauchi, T. Goya, et al., Diagnostic performance of PET/CT in differentiation of malignant and benign nonsolid solitary pulmonary nodules, Ann Nucl Med 22 (2008) 571-577, http://dx.doi. org/10.1007/s12149-008-0160-1.

[11] D.M. Hansell, A.A. Bankier, H. MacMahon, T.C. McLoud, N.L. Müller, J. Remy, Fleischner Society: glossary of terms for thoracic imaging, Radiology 246 (2008) 697-722, http://dx.doi.org/10.1148/radiol.2462070712.

[12] W.T. Miller, R.M. Shah, Isolated diffuse ground-glass opacity in thoracic CT: causes and clinical presentations, American Journal of Roentgenology 184 (2005) 613-622, http://dx.doi.org/10.2214/ajr.184.2.01840613.

[13] E.J. Chun, H.J. Lee, W.J. Kang, K.G. Kim, J.M. Goo, C.M. Park, et al., Differentiation between malignancy and inflammation in pulmonary ground-glass nodules: The feasibility of integrated 18F-FDG PET/CT, Lung Cancer 65 (2009) 180-186, http:// dx.doi.org/10.1016/j.lungcan.2008.11.015.

[14] F.C. Detterbeck, E.M. Marom, D.A. Arenberg, W.A. Franklin, A.G. Nicholson, W.D. Travis, et al., The IASLC Lung Cancer Staging Project: Background Data and Proposals for the Application of TNM Staging Rules to Lung Cancer Presenting as Multiple Nodules with Ground Glass or Lepidic Features or a Pneumonic Type of Involvement in the Forthcoming Eighth Edition of the TNM Classification, J Thorac Oncol 11 (2016) 666-680, http://dx.doi.org/10.1016/j.jtho.2015.12.113.

[15] K.S. Lee, Y. Kim, J. Han, E.J. Ko, C.K. Park, S.L. Primack, Bronchioloalveolar carcinoma: clinical, histopathologic, and radiologic findings, RadioGraphics 17 (1997) 1345-1357, http://dx.doi.org/10.1148/radiographics.17.6.9397450.

[16] M. Gaeta, S. Vinci, F. Minutoli, S. Mazziotti, G. Ascenti, I. Salamone, et al., CT and MRI findings of mucin-containing tumors and pseudotumors of the thorax: pictorial review, Eur Radiol 12 (2001) 181-189, http://dx.doi.org/10.1007/ s003300100934.

[17] K.L. Berger, S.A. Nicholson, F. Dehdashti, B.A. Siegel, evaluation of mucinous neoplasms: correlation of FDG uptake with histopathologic features, American Journal of Roentgenology 174 (2000) 1005-1008, http://dx.doi.org/10.2214/ajr. 174.4.1741005.

[18] S.A. Groskin, D.M. Panicek, D.K. Ewing, F. Rivera, K. Math, J. Teixeira, et al., Bacterial lung abscess: a review of the radiographic and clinical features of 50 cases, J Thorac Imaging 6 (1991) 62-67.

[19] A. Vourtsi, A. Gouliamos, L. Moulopoulos, X. Papacharalampous, A. Chatjiioannou, D. Kehagias, et al., CT appearance of solitary and multiple cystic and cavitary lung lesions, Eur Radiol 11 (2001) 612-622, http://dx.doi.org/10.1007/ s003300000583.

[20] O. Honda, M. Tsubamoto, A. Inoue, T. Johkoh, N. Tomiyama, S. Hamada, et al. Pulmonary cavitary nodules on computed tomography: differentiation of malignancy and benignancy, J Comput Assist Tomogr 31 (2007) 943-949, http://dx.doi. org/10.1097/RCT.0b013e3180415e20.

[21] J.H. Woodring, A.M. Fried, V.P. Chuang, Solitary cavities of the lung: diagnostic implications of cavity wall thickness, American Journal of Roentgenology 135 (1980) 1269-1271, http://dx.doi.org/10.2214/ajr.135.6.1269.

[22] L.B. Gadkowski, J.E. Stout, Cavitary pulmonary disease, Clin. Microbiol. Rev. 21 (2008) 305-333, http://dx.doi.org/10.1128/cmr.00060-07 table of contents.

[23] W. Li, H. Pang, Q. Liu, J. Zhou, The role of ${ }^{18}$ F-FDG PET or ${ }^{18}$ F-FDG-PET/CT in the evaluation of solitary pulmonary nodules, Eur J Radiol 84 (2015) 2032-2037, http://dx.doi.org/10.1016/j.ejrad.2015.06.008.

[24] F. Gao, X. Ge, M. Li, X. Zheng, L. Xiao, G. Zhang, et al., CT features of lung scar cancer, J Thorac Dis 7 (2015) 273-280, http://dx.doi.org/10.3978/j.issn.20721439.2015.02.07.

[25] Y.I. Kim, J.M. Goo, H.Y. Kim, J.W. Song, J.G. Im, Coexisting bronchogenic carcinoma and pulmonary tuberculosis in the same lobe: radiologic findings and clinical significance, Korean J Radiol 2 (2001) 138-144, http://dx.doi.org/10.3348/kjr. 2001.2.3.138.

[26] K. Brown, D.F. Mund, D.R. Aberle, P. Batra, D.A. Young, Intrathoracic calcifications: radiographic features and differential diagnoses, RadioGraphics 14 (1994) 1247-1261, http://dx.doi.org/10.1148/radiographics.14.6.7855339.

[27] M.C. Mahoney, R.T. Shipley, H.L. Corcoran, B.A. Dickson, CT demonstration of calcification in carcinoma of the lung, American Journal of Roentgenology 154 (1990) 255-258, http://dx.doi.org/10.2214/ajr.154.2.2153329.

[28] A. Lagstein, Pulmonary Apical Cap-What's Old Is New Again, Arch. Pathol. Lab. Med. 139 (2015) 1258-1262, http://dx.doi.org/10.5858/arpa.2015-0224-RA.

[29] J.H. Woodring, Determining the cause of pulmonary atelectasis: a comparison of plain radiography and CT, American Journal of Roentgenology 150 (1988)
757-763, http://dx.doi.org/10.2214/ajr.150.4.757.

[30] P.L. Molina, J.N. Hiken, H.S. Glazer, Imaging evaluation of obstructive atelectasis, Thorac Imaging 11 (1996) 176-186.

[31] A.K. Vaaler, J.M. Forrester, M. Lesar, M. Edison, D. Venzon, B.E. Johnson, Obstructive atelectasis in patients with small cell lung cancer. Incidence and response to treatment, Chest 111 (1997) 115-120.

[32] R.-M. Yang, L. Li, X.-H. Wei, Y.-M. Guo, Y.-H. Huang, L.-S. Lai, et al., Differentiation of central lung cancer from atelectasis: comparison of diffusion-weighted MRI with PET/CT, PLoS ONE 8 (2013) e60279, http://dx.doi.org/10.1371/journal.pone. 0060279.

[33] B.W. Carter, B.S. Glisson, M.T. Truong, J.J. Erasmus, Small Cell Lung Carcinoma: Staging, Imaging, and Treatment Considerations, RadioGraphics 34 (2014) 1707-1721, http://dx.doi.org/10.1148/rg.346140178.

[34] S. Chong, K.S. Lee, M.J. Chung, J. Han, O.J. Kwon, T.S. Kim, Neuroendocrine tumors of the lung: clinical, pathologic, and imaging findings, RadioGraphics 26 (2006), http://dx.doi.org/10.1148/rg.261055057 41-57-discussion 57-8.

[35] R.E.C. Benson, M.L. Rosado-de-Christenson, S. Martínez-Jiménez, J.R. Kunin, P.P. Pettavel, Spectrum of pulmonary neuroendocrine proliferations and neoplasms, RadioGraphics 33 (2013) 1631-1649, http://dx.doi.org/10.1148/rg.336135506.

[36] N.A. Womack, E.A. Graham, Epithelial metaplasia in congenital cystic disease of the lung: Its possible relation to carcinoma of the bronchus, Am. J. Pathol. 17 (1941) 645-654.5.

[37] M. Mascalchi, D. Attinà, E. Bertelli, M. Falchini, A. Vella, A.L. Pegna, et al., Lung cancer associated with cystic airspaces, J Comput Assist Tomogr 39 (2015) 102-108, http://dx.doi.org/10.1097/RCT.0000000000000154.

[38] T. Yoshida, T. Harada, S. Fuke, J. Konishi, K. Yamazaki, M. Kaji, et al., Lung adenocarcinoma presenting with enlarged and multiloculated cystic lesions over 2 years, Respir Care 49 (2004) 1522-1524.

[39] M. Kaneda, T. Tarukawa, F. Watanabe, K. Adachi, T. Sakai, H. Nakabayashi, Clinical features of primary lung cancer adjoining pulmonary bulla, Interactive CardioVascular and Thoracic Surgery 10 (2010) 940-944, http://dx.doi.org/10. 1510/icvts.2010.233551.

[40] A.O. Farooqi, M. Cham, L. Zhang, M.B. Beasley, J.H.M. Austin, A. Miller, et al., Lung cancer associated with cystic airspaces, AJR Am J Roentgenol 199 (2012) 781-786, http://dx.doi.org/10.2214/AJR.11.7812.

[41] D. Maki, M. Takahashi, K. Murata, S. Sawai, S. Fujino, S. Inoue, Computed tomography appearances of bronchogenic carcinoma associated with bullous lung disease, J Comput Assist Tomogr 30 (2006) 447-452.

[42] F.J. Fintelmann, J.K. Brinkmann, W.R. Jeck, F.M. Troschel, S.R. Digumarthy, M. Mino-Kenudson, et al., Lung Cancers Associated With Cystic Airspaces, J Thorac Imaging (2017) 1-13, http://dx.doi.org/10.1097/rti.0000000000000265.

[43] C. Casali, M. Cucca, G. Rossi, F. Barbieri, L. Iacuzio, B. Bagni, et al., The variation of prognostic significance of Maximum Standardized Uptake Value of [18F]-fluoro-2deoxy-glucose positron emission tomography in different histological subtypes and pathological stages of surgically resected Non-Small Cell Lung Carcinoma, Lung Cancer 69 (2010) 187-193, http://dx.doi.org/10.1016/j.lungcan.2009.10.015.

[44] H. Nakamura, H. Saji, T. Shinmyo, R. Tagaya, N. Kurimoto, H. Koizumi, et al., Close association of IASLC/ATS/ERS lung adenocarcinoma subtypes with glucose-uptake in positron emission tomography, Lung Cancer 87 (2015) 28-33, http://dx.doi.org/ 10.1016/j.lungcan.2014.11.010.

[45] A.C. Nachiappan, K. Rahbar, X. Shi, E.S. Guy, E.J. Mortani Barbosa, G.S. Shroff, et al. Pulmonary Tuberculosis: Role of Radiology in Diagnosis and Management, RadioGraphics 37 (2017) 52-72, http://dx.doi.org/10.1148/rg.2017160032.

[46] C.M. Jude, N.B. Nayak, M.K. Patel, M. Deshmukh, P. Batra, Pulmonary coccidioidomycosis: pictorial review of chest radiographic and CT findings, RadioGraphics 34 (2014) 912-925, http://dx.doi.org/10.1148/rg.344130134.

[47] E.J. Escott, A Variety of Appearances of Malignant Melanoma in the Head: A Review, RadioGraphics 21 (2001) 625-639, http://dx.doi.org/10.1148/ radiographics.21.3.g01ma19625.

[48] S. Mukhopadhyay, A.A. Gal, Granulomatous lung disease: an approach to the differential diagnosis, Arch. Pathol. Lab. Med. 134 (2010) 667-690, http://dx.doi.org/ 10.1043/1543-2165-134.5.667.

[49] E. Laack, R. Simon, M. Regier, B. Andritzky, P. Tennstedt, C. Habermann, et al. Miliary never-smoking adenocarcinoma of the lung: strong association with epidermal growth factor receptor exon 19 deletion, J Thorac Oncol 6 (2011) 199-202, http://dx.doi.org/10.1097/JTO.0b013e3181fb7cf1.

[50] S.-G. Wu, F.-C. Hu, Y.-L. Chang, Y.-C. Lee, C.-J. Yu, Y.-C. Chang, et al., Frequent EGFR mutations in nonsmall cell lung cancer presenting with miliary intrapulmonary carcinomatosis, Eur. Respir. J. 41 (2013) 417-424, http://dx.doi. org/10.1183/09031936.00006912. 